\title{
Aggregation State of Molecular Chains and Dynamic Mechanical Behavior of Poly(L-glutamic acid)
}

\author{
Tetsuo MORI, Akihiko MOROFuJI, and Ryuichi TANAKA \\ Department of Materials Science and Technology, Kyushu University, \\ 6-10-1 Hakozaki, Fukuoka 812, Japan.
}

(Received April 26, 1979)

\begin{abstract}
The structure and the dynamic mechanical properties of solid films of poly(Lglutamic acid) (PGA), which were cast from $N, N$-dimethylformamide (DMF) and dioxane (D)-water (W) mixtures $\left(1: 2,1: 1,2: 1,3: 1,4: 1\right.$, and $6: 1$ by volume) at $60^{\circ} \mathrm{C}$, were investigated. Three different types of PGA films were obtained: (1) films cast from D-W $(1: 2)$ and D-W $(1: 1)$ had a high crystallinity, (2) films cast from D-W (2:1), D-W $(3: 1)$, and D-W (4:1) had pale cholesteric colors, and (3) films cast from D-W (6:1) and DMF had a lower crystallinity. From dynamic mechanical measurements, at least five relaxational modes were recognized between room temperature and $210^{\circ} \mathrm{C}$. The $\alpha$-relaxation observed at $200-210^{\circ} \mathrm{C}(3.5 \mathrm{~Hz})$ was assigned to the thermal degradation. The $\beta$-relaxation observed at $140-160^{\circ} \mathrm{C}(3.5 \mathrm{~Hz})$ may be a crystalline relaxation such as a molecular motion of $\alpha$-helices of PGA in the crystalline region or a mutual displacement of neighboring crystallites. The $\gamma$-relaxation observed at $115-130^{\circ} \mathrm{C}(3.5 \mathrm{~Hz})$ was assinged to the micro-Brownian motions of $\alpha$-helices in the disordered region. The $\delta$-relaxation observed at $60-95^{\circ} \mathrm{C}(3.5 \mathrm{~Hz})$ may be associated with the side chain motions caused by the rupture of hydrogen bonds between carboxyl groups. The $\varepsilon$-relaxation observed at $20-45^{\circ} \mathrm{C}(3.5 \mathrm{~Hz})$ was assigned to the side chain motions in the disordered region.
\end{abstract}

KEY WORDS Poly(L-glutamic acid) / Cast Film / Aggregation State / Mechanical Relaxation / $\alpha$-Helix /

It is well known that the cholesteric liquid crystals are formed in concentrated solutions of synthetic polypeptides. ${ }^{1.2}$ The structure and the properties of the solid films preared by casting such solutions will depend very much on casting conditions, such as solvent, temperature, evaporation rate of solvent, etc.

Samulski et al. ${ }^{3}$ Tachibana et al.,${ }^{4}$ and Watanabe et al..$^{5,6}$ have found that the cholesteric liquid crystal structure was retained in the solid films of poly $(\gamma-$ benzyl L-glutamate) or poly ( $\gamma$-methyl D-glutamate) (PMG).

Watanabe et $a .^{7}$ and Kajiyama et al. ${ }^{8-10}$ have extensively studied the effects of casting solvents on the structure and the dynamic mechanical relaxation behavior of PMG solid films. But so far there have been only a few studies on the solid films of poly(L-glutamic acid) (PGA) ${ }^{11.12}$

Luzzati et al..$^{13}$ have shown that PGA forms a cholesteric liquid crystal structure in $N, N$-dimethylformamide (DMF) and that the $\alpha$-helices of
PGA are packed in hexagonal lattice in the film prepared by casting the solution.

By means of small-angle light scattering, Wilkes ${ }^{14}$ has demonstrated the existence of spherulitic or rodlike texture in DMF solution of PGA as well as the rod-like texture in the PGA films. The PGA cholesteric liquid crystals can be brought about also in dioxane-water mixtures (D-W 3:1 by volume) and their features can be fixed in the cast films, as reported previously. ${ }^{15}$

The purpose of this paper is to elucidate the relationship between the aggregation state of molecular chains and the dynanic mechanical relaxation behavior of PGA films cast from D-W and DMF.

\section{EXPERIMENTAL}

Materials

Poly(L-glutamic acid) (PGA) was prepared by saponification of poly( $\gamma$-methyl L-glutamate) (Ajicoat A-2000). ${ }^{16}$ The viscosity-average molecular 
weight of PGA was estimated to be 48,000 from its intrinsic viscosity in $0.2 \mathrm{M} \mathrm{NaCl}$ aqueous solution at pH 7.3. ${ }^{17.18}$

PGA films about $0.2-0.3 \mathrm{~mm}$ thick were prepared by casting $6 \mathrm{wt} \%$ solutions of PGA in $N, N$ dimethylformamide (DMF) or dioxane-water mixtures (D-W, 1:2, 1:1, 2:1, 3:1, 4:1, and 6:1 by volume) on a glass plate at $60^{\circ} \mathrm{C}$.

Films of PGA will be designated as PGA(1:1) and PGA(DMF) to represent PGA films cast from D-W (1:1 by volume) and DMF, respectively.

Films of PGA can be classified into three groups: (1) PGA(1:2) amd PGA(1:1) showed a high crystallinity and brittleness, (2) $\operatorname{PGA}(2: 1), \operatorname{PGA}(3: 1)$, PGA(4:1) had a pale iridescent color, suggesting the presence of a cholesteric structure, (3) $\operatorname{PGA}(6: 1)$ and PGA(DMF) showed a lower crystallinity.

All films were dried in vacuo at $100^{\circ} \mathrm{C}$ for at least 2 days before measurements.

\section{Apparatus and Procedures}

Dynamic Measurements. Dynamic measurements were made with a model DDV-IIc Rheovibron at 110,11 , and $3.5 \mathrm{~Hz}$ in the temperature range of -100 to $210^{\circ} \mathrm{C}$. The temperature was raised at a rate of about $1.0-1.5^{\circ} \mathrm{C} / \mathrm{min}$.

$X$-Ray Diffraction. Wide-angle $\mathrm{X}$-ray diffraction patterns were recorded on flat photographic films using a Rigaku Denki Rotaunit RU-3. Nickelfiltered $\mathrm{Cu}-\mathrm{K}_{\alpha}$ radiation was used.

Polarizing Optical Microscopy. Micrographs of thin specimens, sectioned normal to the film surfaces, were taken by a Nikon polarizing microscope type LFG-Ke.

Infrared Absorption Spectroscopy. The temperature dependence of the infrared spectra of PGA (DMF) and PGA (3:1) were measured using a PerkinElmer 567 spectrophotmeter equipped with a heating cell. Very thin films for this measurement were prepared by casting $0.5 \mathrm{wt} \%$ solutions of PGA at $60^{\circ} \mathrm{C}$

Determination of Water Content in $D-W$. The variation of the composition of D-W was followed as a function of time at $60^{\circ} \mathrm{C}$ by the Karl-Fisher determination of water using a Hiranuma Aquacounter Model AQ-2.

Thermogravimetric Analysis (TGA). Thermogravimetric measurements were made using a Shimazu TG-30 at temperatures ranging from room temperature to $260^{\circ} \mathrm{C}$ in air. The rate of heating was $2^{\circ} \mathrm{C} / \mathrm{min}$

\section{RESULTS AND DISCUSSION}

\section{Aggregation state of Molecular Chains}

Infrared Spectra and X-Ray Diffractions. The temperature dependence of an infrared spectrum of PGA (DMF) is shown in Figure 1. The amide I band appeared at $1657 \mathrm{~cm}^{-1}$ and $1651 \mathrm{~cm}^{-1}$, and the amide II band, at $1547 \mathrm{~cm}^{-1}$. These bands are characteristic of polypeptides in the $\alpha$-helix form. ${ }^{16.17}$ The peak positions of the amide I and II bands remain unchanged between $30^{\circ} \mathrm{C}$ and $190^{\circ} \mathrm{C}$, but above $150^{\circ} \mathrm{C}$ a new, small amide-II band arose at ca. $1538 \mathrm{~cm}^{-1}$. This band is usually associated with polypeptides in the $\beta$-form or in the random coil. The

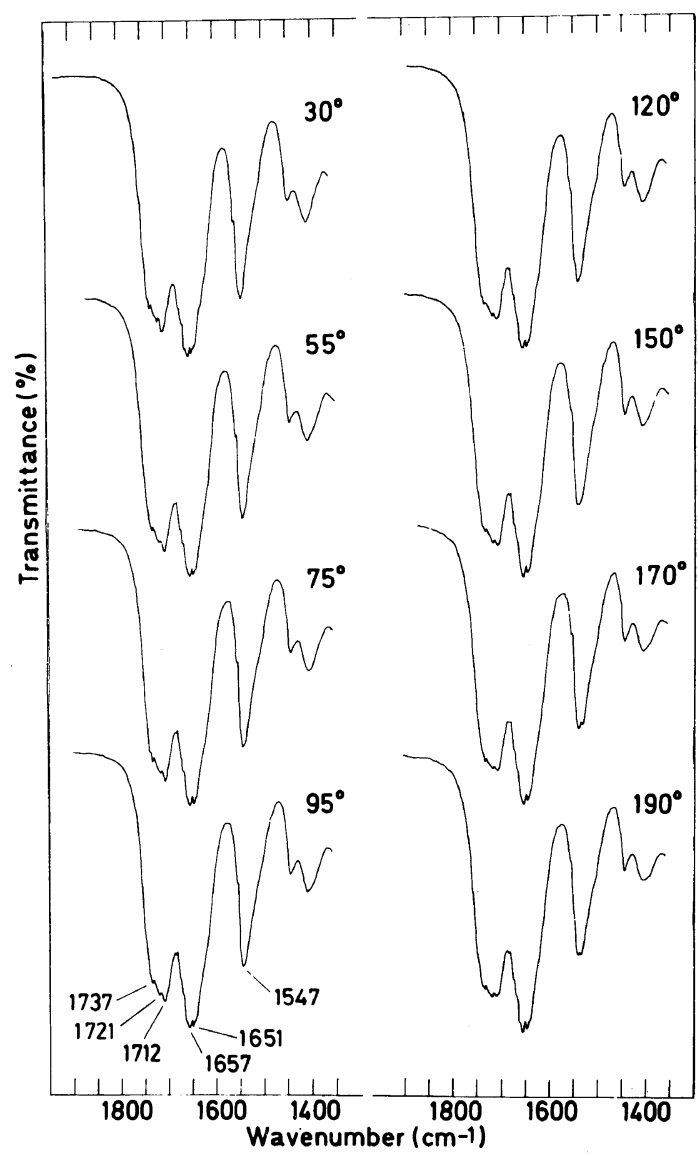

Figure 1. Temperature dependence of an infrared spectrum in the region of $\mathrm{C}=\mathrm{O}$ stretching, amide $\mathrm{I}$ and II bands for PGA (DMF). 


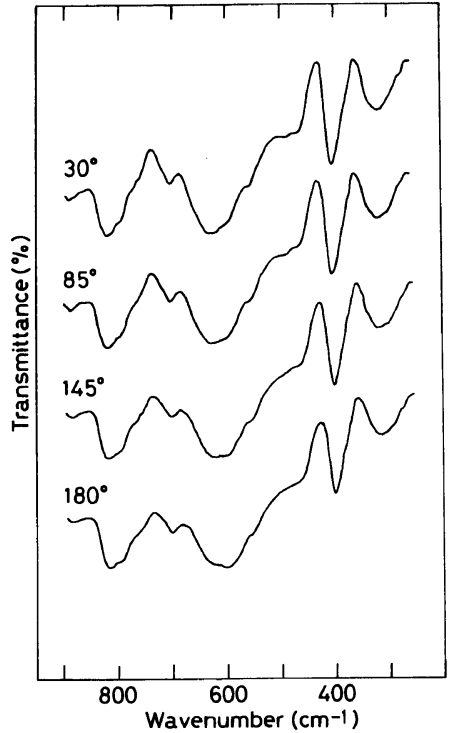

Figure 2. Temperature dependence of an infrared spectrum in the low-frequency region for PGA (DMF).

content of the $\beta$-form or the random coil, however, is probably small because (1) there was no peak at $c a$. $1630 \mathrm{~cm}^{-1}$, characteristic of the $\beta$-form, (2) the amide- $\mathrm{V}$ band ${ }^{17}$ shown in Figure 2, which is very sensitive to $\alpha$-helix $\left(630 \mathrm{~cm}^{-1}\right), \beta$-form $\left(700 \mathrm{~cm}^{-1}\right)$, and random coil $\left(650 \mathrm{~cm}^{-1}\right)$, did not change upon heating, and (3) the characterstic $\alpha$-helix band ${ }^{18}$ observed at ca. $400 \mathrm{~cm}^{-1}$ was very intense from $30^{\circ} \mathrm{C}$ to $180^{\circ} \mathrm{C}$. The PGA molecules in the solid film of PGA (DMF) exist, therefore, predominantly in the $\alpha$-helix form.

Wide-angle X-ray diffraction patterns of PGA(1:2), PGA(1:1), PGA(3:1), and PGA(DMF) are shown in Figure 3. Sharp Debye-Scherrer rings corresponding to $0.93 \mathrm{~nm}$ (vs), $0.47 \mathrm{~nm}(\mathrm{~s})$, $0.39 \mathrm{~nm}(\mathrm{~s}), \quad 0.36 \mathrm{~nm}(\mathrm{~m}), 0.32 \mathrm{~nm}(\mathrm{~m}), 0.28 \mathrm{~nm}(\mathrm{~m})$, and $0.26 \mathrm{~nm}(\mathrm{~m})$ were observed in $\operatorname{PGA}(1: 2)$. PGA(1:1) also showed sharp diffraction rings at $0.96 \mathrm{~nm}(\mathrm{vs}), 0.47 \mathrm{~nm}(\mathrm{~s}), \quad 0.39 \mathrm{~nm}(\mathrm{~m}), 0.28 \mathrm{~nm}(\mathrm{~m})$, and $0.26 \mathrm{~nm}(\mathrm{~m})$. On the other hand, PGA $(3: 1)$ and PGA(DMF) showed a strong diffraction at $c a$. $1.0 \mathrm{~nm}$, but the other three diffraction rings corresponding to $c a .0 .4 \mathrm{~nm}(\mathrm{~m}$, diffuse), $0.28 \mathrm{~nm}(\mathrm{w})$ and $0.26 \mathrm{~nm}(\mathrm{w})$ were very diffuse and weak. The strongest diffractions at $0.90-1.0 \mathrm{~nm}$ observed in every film of PGA were assigned to a (100) reflection of a hexagonal crystal lattice of the $\alpha$-helices. The lattice distance, $d$, and the density, $\rho$, are tabulated in
Table I. (100) spacings $d$ and densities $\rho$ of PGA films

\begin{tabular}{lcc}
\hline & $d / \mathrm{nm}$ & $\rho / \mathrm{g} \mathrm{cm}^{-3 \mathrm{a}}$ \\
\hline PGA $(1: 2)$ & 0.93 & 1.446 \\
PGA $(1: 1)$ & 0.96 & 1.451 \\
PGA $(2: 1)$ & 0.98 & 1.392 \\
PGA (3:1) & 1.03 & 1.391 \\
PGA (6:1) & 1.03 & 1.378 \\
PGA (DMF) & 0.99 & 1.381 \\
\hline
\end{tabular}

a Density was measured by a flotation method using carbon tetrachloride and cyclohexane at $25^{\circ} \mathrm{C}$.

\section{Table I.}

These observations clearly indicate that the degree of crystallinity is on the order of $\operatorname{PGA}(1: 2)$, PGA(1:1) > PGA(2:1), PGA(3:1), PGA(4:1)> PGA (6:1), PGA(DMF).

Polarizing Microscopy. Polarizing micrographs of PGA(1:2), PGA(3:1), PGA(6:1), and PGA(DMF) are shown in Figure 4. In PGA(1:2) and PGA(6:1), finely dispersed optically anisotropic regions were observed, but the aggregation states of $\alpha$-helices looked very different from each other. The anisotropic regions of PGA(1:2) may be crystallites because PGA(1:2) showed a high crystallinity and in addition, precipitation or crystallization of PGA was noted to occur prior to solidification.

The anisotropy in PGA(6:1), on the other hand, may be due mainly to an anisotropic gel because the gel formation was observed during casting and the degree of crystallinity of the film was low.

In PGA(3:1), layered domains with iridescent colors were observed and the existence of the cholesteric liquid crystal structures could be inferred by small-angle light scattering measurements ${ }^{18}$ and the cholesteric colors of the films.

The anisotropic regions in PGA(DMF) may contain both the crystallites and the anisotropic gels because PGA(DMF) showed poor crystallinity.

Thus the structure of PGA films cast from D-W varies greatly, depending on the initial ratio of dioxane and water. This may be related to change in the solvent composition during evaporation of dioxane and water from the solution, affecting the aggregation state of PGA molecules. The variation of the composition of $\mathrm{D}-\mathrm{W}$ with evaporation time at $60^{\circ} \mathrm{C}$ without PGA was measured and is shown in Figure 5. 


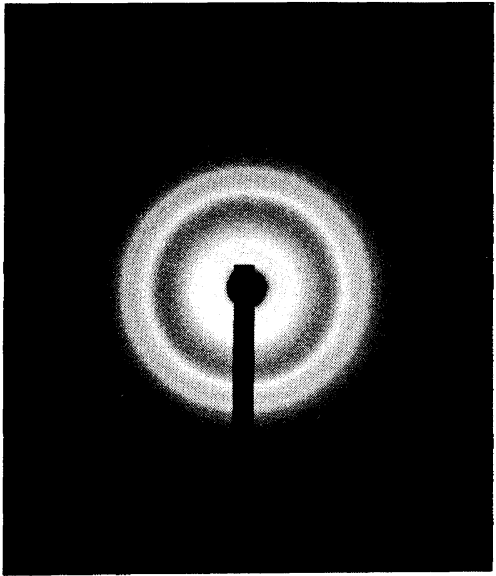

(a)

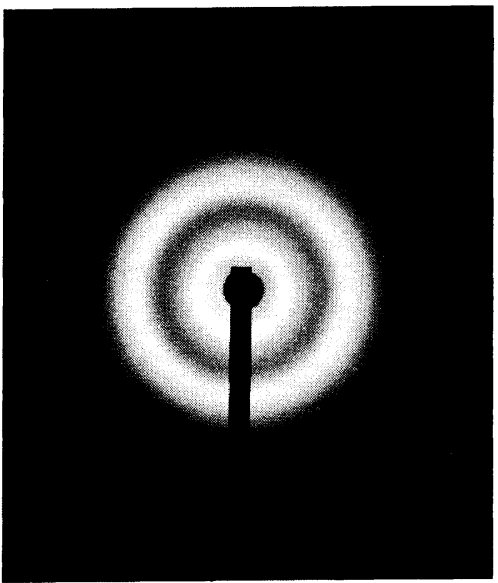

(c)

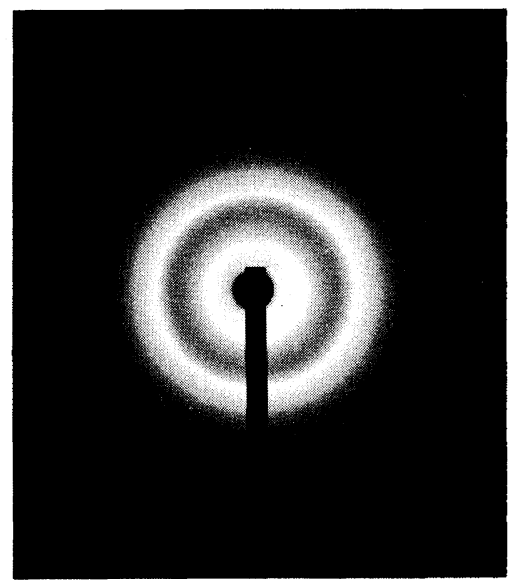

(b)

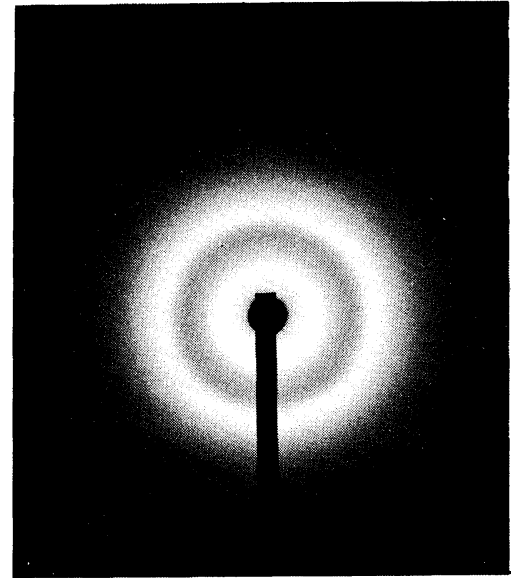

(d)

Figure 3. X-ray diffraction patterns: (a) PGA(1:2); (b) PGA(1:1); (c) PGA(3:1); (d) PGA(DMF).

The composition of D-W(3:1) was almost constant with the lapse of time; the cholesteric liquidcrystal structures in D-W(3:1) may be stable up to higher concentrations of PGA.

The composition of D-W(1:2) becomes gradually richer in water content with time; this may lead to the precipitation of crystalline of PGA. Actually, the D-W(1:2) solution of PGA turned a turbid gel during the evaporation of the solvent and the resultant PGA(1:2) had a high crystallinity.

The composition of D-W(6:1), on the other hand, becomes increasingly richer in dioxane content with evaporation time and gelation may thus occur. The resulting films of PGA, consequently, showed a poor crystallinity.

\section{Dynamic Mechanical Relaxation}

The $\tan \delta$ curves for $\operatorname{PGA}(1: 1), \operatorname{PGA}(3: 1)$, and PGA(DMF) at $3.5 \mathrm{~Hz}$ are shown in Figure 6. Frequency dependence of $\tan \delta$ for $\operatorname{PGA}(1: 1)$, PGA(3:1), and PGA(DMF) are shown in Figures 7, 8 , and 9 , respectively. Five relaxation regions were observed at $200-210^{\circ} \mathrm{C}, 140-160^{\circ} \mathrm{C}, 115-130^{\circ} \mathrm{C}$, $60-95^{\circ} \mathrm{C}$, and $20-45^{\circ} \mathrm{C}$ at $3.5 \mathrm{~Hz}$ and are here denoted $\alpha-, \beta-, \gamma-, \delta$-, and $\varepsilon$-relaxation, respectively.

$\alpha$-Relaxation. The $\alpha$-relaxation in the temperature range from $200^{\circ} \mathrm{C}$ to $210^{\circ} \mathrm{C}$ at $3.5 \mathrm{~Hz}$ appeared to be associated with the samples of low crystallinity, namely, PGA(6:1) and PGA(DMF). The $\tan \delta$ curves for PGA(1:2) and PGA(1:1), which had a high degree of crystallinity, showed no $\alpha$-relaxation. After 


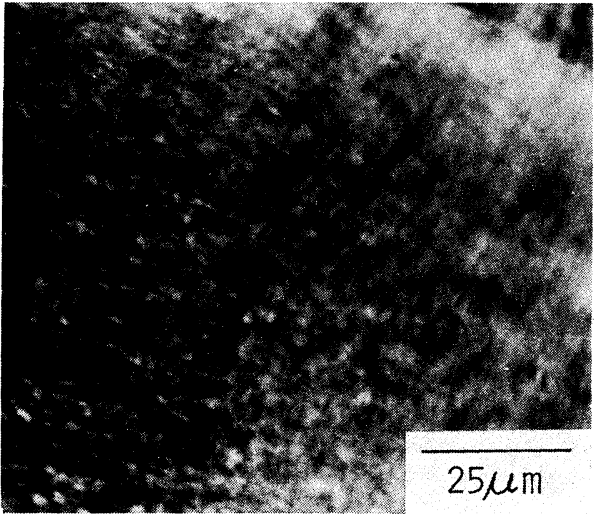

(a)

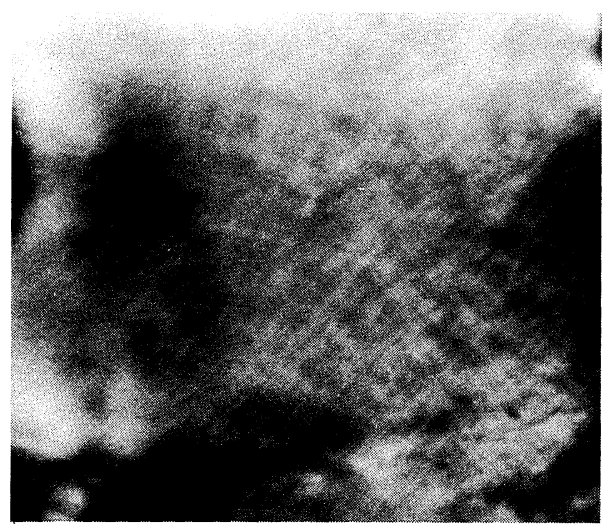

(c)

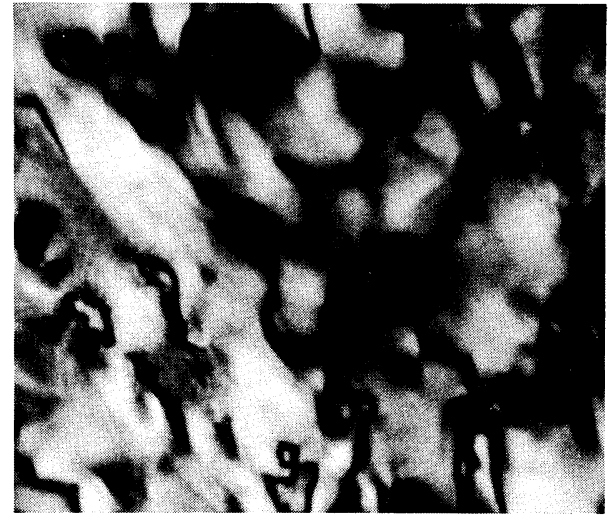

(b)

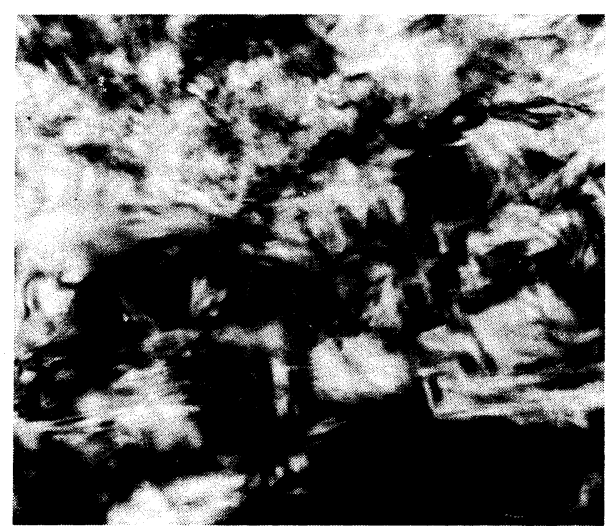

(d)

Figure 4. Polarizing micrographs of PGA films: (a) PGA(1:2); (b) PGA(3:1); (c) PGA(6:1); (d) PGA(DMF).

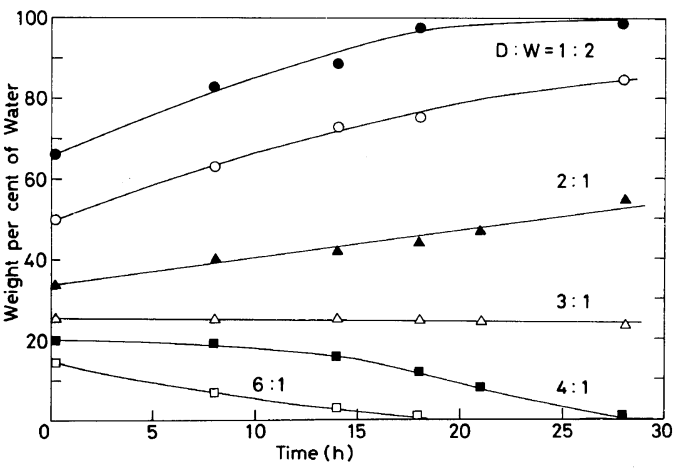

Figure 5. Time dependence of the composition of dioxane-water mixtures at $60^{\circ} \mathrm{C}$ under casting conditions.

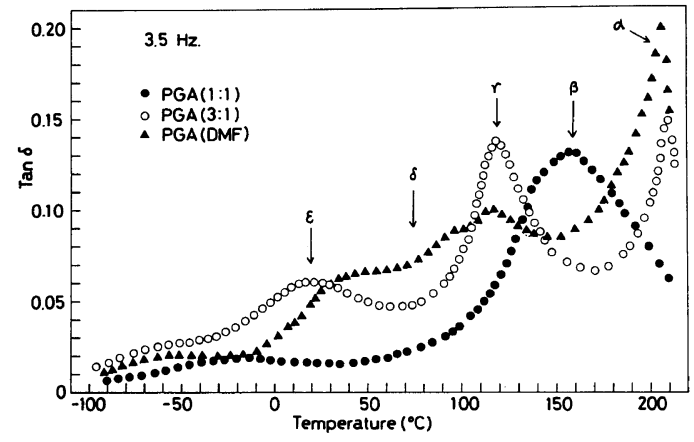

Figure 6. Temperature dependence of $\tan \delta$ for PGA(1:1), PGA(3:1), and PGA(DMF) at $3.5 \mathrm{~Hz}$. 


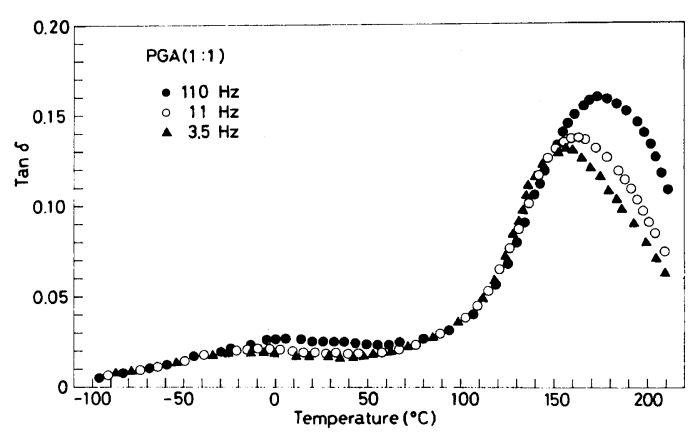

Figure 7. Frequency dependence of $\tan \delta$ for $\operatorname{PGA}(1: 1)$.

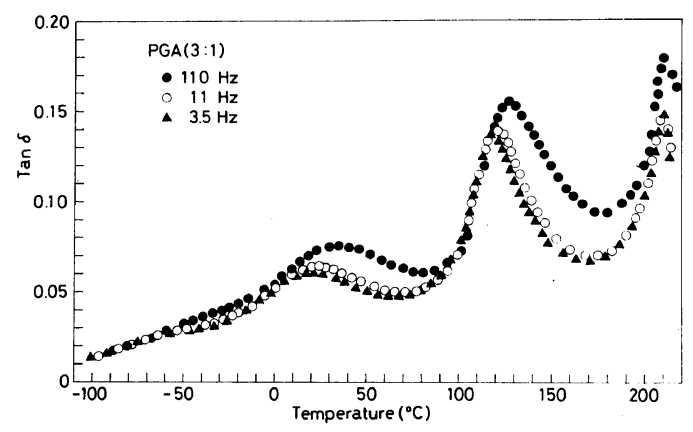

Figure 8. Frequency dependence of $\tan \delta$ for $\operatorname{PGA}(3: 1)$.

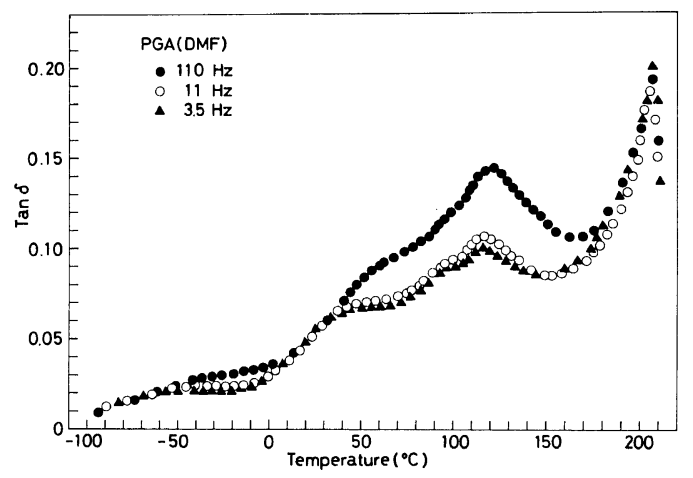

Figure 9. Frequency dependence of $\tan \delta$ for PGA(DMF).

dynamic mechanical measurements were made up to $210^{\circ} \mathrm{C}$, the specimens were slighly yellow, indicating thermal degradation of PGA. TGA curves for PGA(1:1), PGA(3:1), and PGA(DMF) are shown in Figure 10. PGA(3:1) and PGA(DMF) began to degrade gradually at $140-145^{\circ} \mathrm{C}$, with weight losses at $200^{\circ} \mathrm{C}$ of 5.2 and $3.7 \%$, respectively. On the other

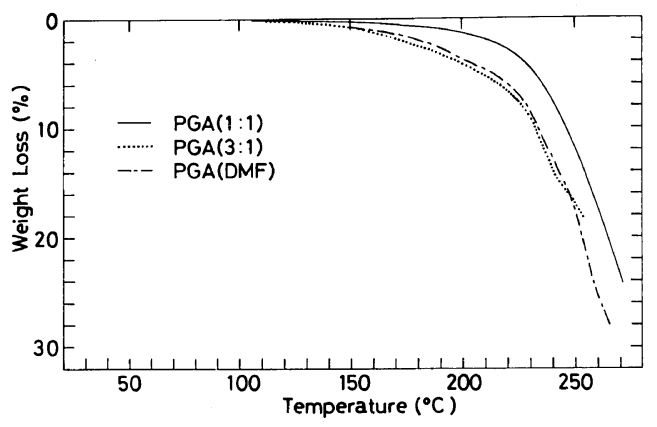

Figure 10. TGA curves for PGA(1:1), PGA(3:1), and PGA(DMF).

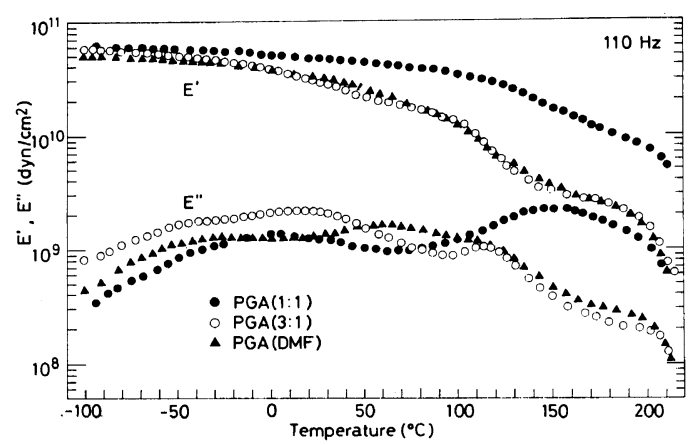

Figure 11. Temperature dependence of the dynamic storage modulus $E^{\prime}$ and the dynamic loss modulus $E^{\prime \prime}$ at $110 \mathrm{~Hz}$ for PGA(1:1), PGA(3:1), and PGA(DMF).

hand, degradation of PGA(1:1) started at 160 $170^{\circ} \mathrm{C}$ and the weight loss at $200^{\circ} \mathrm{C}$ was only $1.4 \%$. Perhaps, the first step of the thermal degradation was the formation of anhydrides from carboxyl groups. PGA(1:2) and PGA(1:1) with high degrees of crystallinity are expected to be more resistant to degradation than other films of PGA. This difference in the thermal stability of the PGA films is reflected in the dynamic storage modulus, $E^{\prime}$, as shown in Figure 11: $E^{\prime}$ at $210^{\circ} \mathrm{C}$ of $\mathrm{PGA}(1: 1)$ was greater by one order of magnitude than those of $\operatorname{PGA}(3: 1)$ and PGA(DMF).

Thus the $\alpha$-relaxation occurring from $200^{\circ} \mathrm{C}$ to $210^{\circ} \mathrm{C}$ is associated with the onset of the thermal degradation.

$\beta$ - and $\gamma$-Relaxation. The dynamic mechanical properties of polypeptides, especially of $\operatorname{poly}(\gamma-$ methyl D-glutamate) (PMG), have been extensively studied but the mechanisms of the relaxations which appear above $100^{\circ} \mathrm{C}$ have not been well established. 
The relaxation at about $160^{\circ} \mathrm{C}(110 \mathrm{~Hz})$ for $\mathrm{PMG}$ has been attributed to the mutual slip or the rotational deformation of $\alpha$-helices in the crystalline region by Kajiyama et al., ${ }^{9}$ but according to Sakamoto et $a l^{22.23}$ and Watanabe et al., this is due to molecular motions of $\alpha$-helices in the disordered region. Furthermore, the relaxation at about $190^{\circ} \mathrm{C}(110 \mathrm{~Hz})$ for PMG has been attributed to the tensile or the bending deformation of $\alpha$-helices in the crystalline region $^{9}$ or to the molecular motions of $\alpha$-helices in the crystalline region or mutual displacement of the neighboring crystallites. ${ }^{7.22 .23}$ Kajiyama et al. ${ }^{10}$ have also attributed the relaxation from $100^{\circ} \mathrm{C}$ to $120^{\circ} \mathrm{C}$ $(110 \mathrm{~Hz})$ for PMG to the micro-Brownian motions of $\alpha$-helices.

We are now inclined to believe that the $\beta$ - and the $\gamma$-relaxations of PGA are associated with the crystalline and disordered regions, respectively, based on the following observations. First, the $\alpha$-relaxation at $140^{\circ} \mathrm{C}$ to $160^{\circ} \mathrm{C}(3.5 \mathrm{~Hz})$ was observed in PGA $(1: 2)$ and PGA(1:1) with high degrees of crystallinity; the $\gamma$-relaxation from $115^{\circ} \mathrm{C}$ to $130^{\circ} \mathrm{C}(3.5 \mathrm{~Hz})$, on the other hand, was observed in PGA(2:1), PGA(3:1), PGA(4:1), PGA(6:1), and PGA(DMF) with low degrees of crystallinity. Second, the apparent activation energies $\left(\Delta H^{*}\right)$ determined from Figures 7 9 , for the $\beta$ - and the $\gamma$-relaxations were $70-80$ and $100-120 \mathrm{kcal} \mathrm{mol}^{-1}$, respectively. That is, in spite of the higher peak temperature of the $\beta$-relaxation than that of the $\gamma$-relaxation, the $\Delta H^{*}$ for the $\beta$-relaxation was smaller than that for the $\gamma$-relaxation. This suggests that the relaxation mechanism for the $\beta$ process is different from that for the $\gamma$-process. In order to clarify this, the dynamic mechanical properties of a stretched specimen of PGA(3:1) were measured (Figure 12). A PGA(3:1) film containing $5.2 \mathrm{wt} \%$ of D-W was stretched to a draw ratio of 2.1 at room temperature and dried in vacuo at $100^{\circ} \mathrm{C}$. The $\tan \delta$ curve and the dynamic storage modulus, $E^{\prime}$, of the stretched PGA(3:1) became very similar to those of PGA(1:2), i.e., (1) the $\alpha$-peak of the unstretched PGA(3:1) disappeared, (2) the $\gamma$-peak of the unstretched PGA(3:1) almost disappeared and the $\beta$-peak appeared, (3) the intensity of the relaxation near room temperature ( $\varepsilon$-relaxation) decreased, and (4) $E^{\prime}$ increased significantly. These changes can be explained by an increase in the degree of crystallinity caused by stretching. These results clearly support the above-mentioned assignments of the $\beta$ - and $\gamma$-relaxations.
Taking into consideration the similarities of films of synthetic polypeptides ${ }^{3.8}$ and crosslinked poly(Lglutamic acid) to the liquid-crystal structures,${ }^{24}$ the unstretched PGA(3:1) should have a layered structure comprising cholesteric liquid-crystal domains with the cholesteric axis nearly perpendicular to the film surfaces, and in each domain, $\alpha$-helices tend to orient along the stretching direction. This is supported by necking observed in the course of stretching and by an increase in the density from 1.391 for the unstretched PGA(3:1) to 1.411 for the stretched PGA(3:1).

The dynamic mechanical properties of the stretched specimen of PGA(DMF) is shown in Figure 13. PGA(DMF) containing $7.1 \mathrm{wt} \%$ of DMF was stretched to a draw ratio of 2.1 at room temperature and dried in vacuo at $100^{\circ} \mathrm{C}$. With stretching, (1) the $\alpha$-peak intensity decreased, (2) the $\gamma$-peak temperature shifted to a slightly higher temperature, and (3) the intensity of the $\delta$-relaxation $\left(60-95^{\circ} \mathrm{C}, 3.5 \mathrm{~Hz}\right)$ decreased. But the change in the relaxation curve for PGA(DMF), as a whole, was smaller than that in $\operatorname{PGA}(3: 1)$. This is perhaps because crystallization by stretching was less for PGA(DMF) than for PGA(3:1), since the aggregation state of the $\alpha$-helices in the amorphous region was rather disordered for the unstretched PGA(DMF) as compared to PGA(3:1). This is supported by the facts that no necking took place and that the density slightly changed by stretching the PGA(DMF).

$\delta$-Relaxation. In the $\tan \delta$ curve for PGA(DMF), a very broad dispersion ( $\delta$-dispersion) was observed in the temperature range from $60^{\circ} \mathrm{C}$ to $95^{\circ} \mathrm{C}$. This broadness of the $\tan \delta$ curve suggests that various aggregation states of PGA molecules exist in PGA(DMF).

In the infrared spectra of PGA(DMF) shown in Figure 1, there are three peaks in the range of $1700 \mathrm{~cm}^{-1}$ to $1750 \mathrm{~cm}^{-1}$ due to the $\mathrm{C}=\mathrm{O}$ stretching vibration of the carboxyl group: $1737 \mathrm{~cm}^{-1}$ due to the nonhydrogen-bonded carbonyl, $1721 \mathrm{~cm}^{-1}$ and $1712 \mathrm{~cm}^{-1}$ due to the hydrogen-bonded carbonyl. On heating the films of PGA(DMF) from $55^{\circ} \mathrm{C}$ to $190^{\circ} \mathrm{C}$, the relative intensity of the $1737 \mathrm{~cm}^{-1}$ gradually increased and that of the $1712 \mathrm{~cm}^{-1}$ gradually decreased, suggesting that the hydrogen bonds between the carboxyl groups begin to beak around $55^{\circ} \mathrm{C}$ and the motions of the side chains are thus facilitated. 
T. Mori, A. Morofuni, and R. TANakA

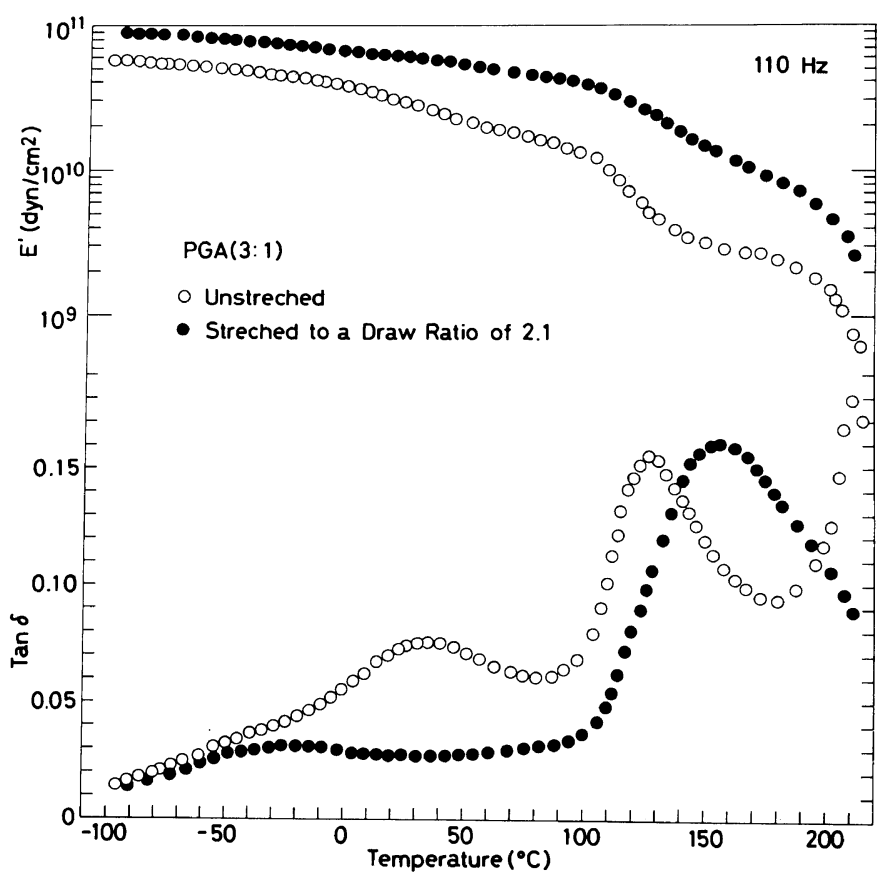

Figure 12. Effect of stretching on the dynamic mechanical properties of $\operatorname{PGA}(3: 1)$.

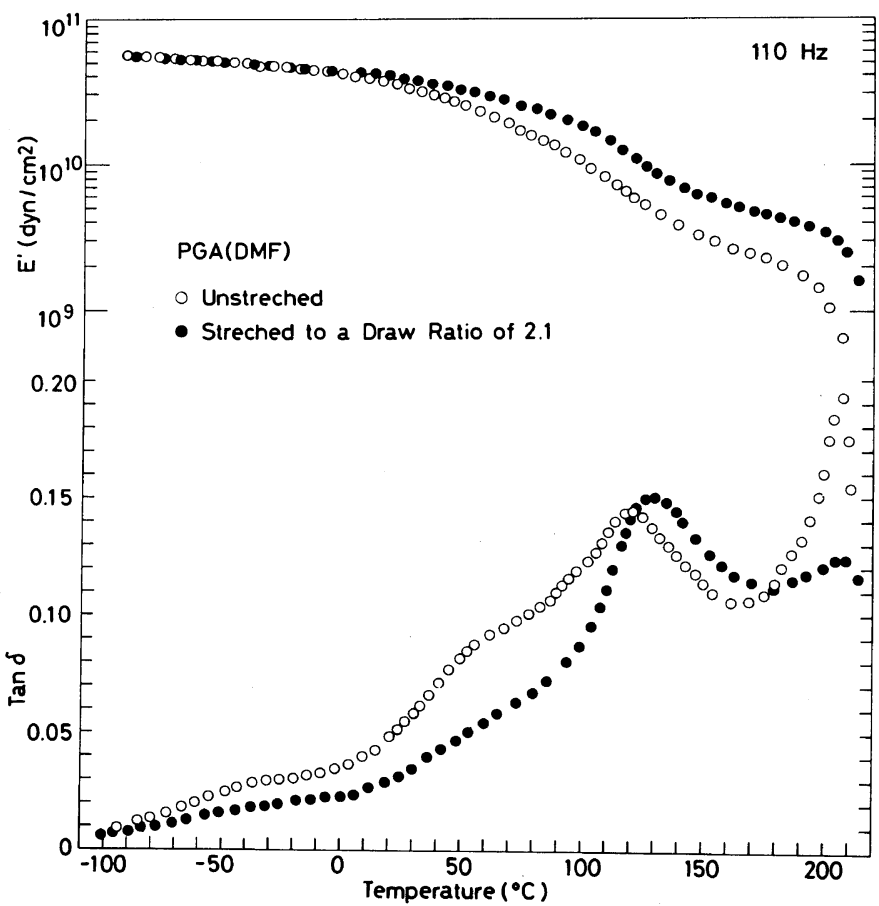

Figure 13. Effect of stretching on the dynamic mechanical properties of PGA(DMF). 
Thus, the $\delta$-ralaxation is attributed to the sidechain motions caused by the breaking of the hydrogen bonds between the carboxyl group.

$\varepsilon$-Relaxation. It is certain that the relaxation which occurred near room temperature in esters of poly(glutamic acid) is associated with the side-chain motions..$^{25-27}$ Similarly, the $\varepsilon$-relaxation of PGA, observed in the temperature range from $20^{\circ} \mathrm{C}$ to $45^{\circ} \mathrm{C}(3.5 \mathrm{~Hz})$, should be attributed to the side chain motions of PGA in the amorphous region. This assignment is confirmed by the following observations: (1) $\Delta H^{*}$ for this relaxation was 20 to $40 \mathrm{kcal} \mathrm{mol}^{-1}$, and (2) the intensities of the $\varepsilon$-relaxations for PGA(DMF), PGA(3:1), and PGA(6:1), which showed low crystallinities, were stronger than those for PGA(1:2) and $\mathrm{PGA}(1: 1)$, which showed high crystallinities.

Acknowledgment. This study was supported by a Grand in Aid for Scientific Research from the Ministry of Education (No. 375482), Japan.

\section{REFERENCES}

1. C. Robinson, Trans. Faraday Soc., 52, 571 (1956).

2. C. Robinson, J. C. Ward, and R. B. Beevers, Discuss. Faraday Soc., 25, 29 (1958).

3. E. T. Samulski and A. V. Tobolsky, Nature, 216, 997 (1967).

4. T. Tachibana and E. Oda, Bull. Chem. Soc. Jpn., 46, (1973).

5. J. Watanabe, S. Sasaki, and I. Uematsu, Polym. J., 9, 337 (1977).

6. J. Watanabe, S. Sasaki, and I. Uematsu, Polym. J., 9, 451 (1977).

7. J. Watanabe, M. Naka, J. Watanabe, K. Watanabe, and I. Uematsu, Polym. J., 10, 569 (1978).
8. K. Ito, T. Kajiyama, and M. Takayanagi, Polym. J., 9, 355 (1977).

9. T. Kajiyama, M. Kuroishi, and M. Takayanagi, J. Macromol. Sci., Phys., B11, 121 (1975).

10. T. Kajiyama, M. Kuroishi, and M. Takayanagi, $J$. Macromol. Sci., Phys., B11, 195 (1975).

11. A. Nguyen, B. T. Vu, and G. L. Wilkes, J. Macromol. Sci., Phys., B9, 367 (1974).

12. T. Mori, Y. Kuchihara, R. Tanaka, and T. Tanaka, $J$. Polym. Sci., Polym. Phys. Ed., 12, 501 (1974).

13. P. Saludjian, C. de Loze, and V. Lussati, C. R., 256, 4514 (1963).

14. G. L. Wilkes, Mol. Cryst. Liq. Cryst., 18, 165 (1972).

15. T. Mori, T. Yamada, R. Tanaka, and T. Tanaka, Kobunshi Ronbunshu, 36, 183 (1979).

16. Y. Takeda, K. Okuda, and S. Sakurai (Ajinomoto Co. Ltd.), Japanese Patent 3290 (1965).

17. A. Wada, Mol. Phys., 3, 409 (1960).

18. B. R. Jennings, G. Spach, and T. M. Schuster, Biopolymers, 6, 635 (1968).

19. H. Lenormant, A. Baudras, and E. R. Blout, J. Am. Chem. Soc., 80, 6191 (1958).

20. Y. Masuda, K. Fukushima, T. Fuji, and T. Miyazawa, Biopolymers, 8, 91 (1959).

21. T. Miyazawa, "Poly- $\alpha$-amino Acids", G. D. Fasman, Ed., Marcel Dekker Inc., New York, N. Y., 1967, p 69.

22. M. Ichikawa, R. Sakamoto, Y. Abe, and K. Makishima, Kobunshi Kagaku, 30, 346 (1973).

23. T. Noda, Y. Abe, and R. Sakamoto, Kobunshi Ronbunshu, 31, 203 (1974).

24. T. Mori, R. Tanaka, and T. Tanaka, Polymer, 18, 1041 (1977).

25. A Hiltner, J. M. Anderson, and E. Borkowski, Macromolecules, 5, 446 (1972).

26. K. Hikichi, A. Tsutsumi, S. Isozaki, and M. Kaneko, Polym. J., 7, 646 (1975).

27. N. Matsushima, K. Hikichi, A. Tsutsumi, and M. Kaneko, Polym. J., 7, 44 (1975). 